Article

\title{
Amine-Functionalized Sugarcane Bagasse: A Renewable Catalyst for Efficient Continuous Flow Knoevenagel Condensation Reaction at Room Temperature
}

\author{
Yanhui Qiao ${ }^{1,2}$, Junjiang Teng ${ }^{2}$, Shuangfei Wang ${ }^{1,3, *}$ and Hao $\mathrm{Ma}^{2, *}$ \\ 1 School of Chemistry and Chemical Engineering, Guangxi University, Nanning 530004, China; \\ qyhmmc@gdupt.edu.cn \\ 2 College of Chemical Engineering, Guangdong University of Petrochemical Technology, Maoming 525000, \\ China; tjjteng@gdupt.edu.cn \\ 3 College of Light Industry and Food Engineering, Guangxi University, Nanning 530004, China \\ * Correspondence: wangsf@gxu.edu.cn (S.W.); thma@gdupt.edu.cn (H.M.)
}

Received: 29 November 2017; Accepted: 22 December 2017; Published: 24 December 2017

\begin{abstract}
A biomass-based catalyst with amine groups $\left(-\mathrm{NH}_{2}\right)$, viz., amine-functionalized sugarcane bagasse (SCB- $\mathrm{NH}_{2}$ ), was prepared through the amination of sugarcane bagasse (SCB) in a two-step process. The physicochemical properties of the catalyst were characterized through FT-IR, elemental analysis, $\mathrm{XRD}, \mathrm{TG}$, and SEM-EDX techniques, which confirmed the $-\mathrm{NH}_{2}$ group was grafted onto $\mathrm{SCB}$ successfully. The catalytic performance of $\mathrm{SCB}-\mathrm{NH}_{2}$ in Knoevenagel condensation reaction was tested in the batch and continuous flow reactions. Significantly, it was found that the catalytic performance of SCB- $\mathrm{NH}_{2}$ is better in flow system than that in batch system. Moreover, the SCB- $\mathrm{NH}_{2}$ presented an excellent catalytic activity and stability at the high flow rate. When the flow rate is at the $1.5 \mathrm{~mL} / \mathrm{min}$, no obvious deactivation was observed and the product yield and selectivity are more than $97 \%$ and $99 \%$ after $80 \mathrm{~h}$ of continuous reaction time, respectively. After the recovery of solvent from the resulting solution, a white solid was obtained as a target product. As a result, the SCB- $\mathrm{NH}_{2}$ is a promising catalyst for the synthesis of fine chemicals by Knoevenagel condensation reaction in large scale, and the modification of the renewable $\mathrm{SCB}$ with $-\mathrm{NH}_{2}$ group is a potential avenue for the preparation of amine-functionalized catalytic materials in industry.
\end{abstract}

Keywords: sugarcane bagasse; amine catalyst; Knoevenagel condensation; flow reaction; room temperature

\section{Introduction}

The Knoevenagel condensation, as one of the most classic methods for carbon-carbon bond formation in organic synthesis [1], is widely employed in the synthesis of high value-added chemicals such as therapeutic drugs, natural products, fine chemicals, carbocyclic and heterocyclic compounds of biological significance [2]. Normally, this reaction is proceeded in the presence of a basic catalyst through the nucleophilic addition of a carbanion to an electrophilic carbonyl group followed by a spontaneous dehydration process [3]; and the relatively weak base catalysts, viz., amine catalysts (such as aliphatic amines, urea and piperidine) or ammonia and their salts, are the preferred choices [4]. However, it is difficult to meet the increasing recoverability and recyclability criteria of these catalysts in a green and sustainable way in spite of the high catalytic activity. Thus, various solid catalysts with amine groups $\left(-\mathrm{NH}_{2}\right)$ have been developed in recent decades.

In heterogeneous catalysis, the continuous reaction through the flow process has attracted much more attention [5]. Compared with traditional batch systems, the product yield, selectivity, 
quality and reproducibility are increased with continuous flow. Furthermore, the production costs, solvent consumption, and waste generation are also decreased with the continuous flow process $[6,7]$. The continuous flow processing can be regarded as an emerging technology with the environmental and economic advantages in dealing with reactive intermediates or energetic materials to achieve the continuous "scaled out" processes in chemical and pharmaceutical industries [8-12]. At present, the efforts on the utilization of the continuous flow process in Knoevenagel condensation reaction have been reported. For example, Wiles et al. [13] utilized 3-(1-piperazino)propyl-functionalized silica gel as the catalyst, and EOF-based micro-fabricated device as the flow reactor for Knoevenagel condensation reaction, presenting high yields $(>99 \%)$ and product purity in all cases. Zhang et al. [14] have fabricated a stable ZIF-8/NaA composite membrane microreactor for the continuous flow Knoevenagel condensation, achieving nearly $100 \%$ product yield in a short residence time under mild conditions. Tsutsumi et al. [15] prepared a basic nanofibrillar chitin aerogel as the renewable catalyst for Knoevenagel condensation, which presented high performance in flow mode. Xu et al. [16] designed a basic organocatalyst through the immobilization of DABCO on polystyrene support. The prepared polystyrene-immobilized DABCO catalyst presents the high catalytic activity in both batch and continuous flow reactor with excellent selectivity and short reaction time. Therefore, the utilization of the solid amine catalyst for the continuous flow Knoevenagel condensation reaction is a promising way to the synthesis of the high value-added chemicals. The solid amine catalysts are commonly prepared through the functionalization of the support with $-\mathrm{NH}_{2}$ group. The supports are classified into molecular sieves [17,18], metal organic framework [19-22], polymers [16,23], graphene oxide [24,25], and others [26-29]. However, the utilization of most of these supports suffers from one or more drawbacks such as the harsh preparation conditions, equipment corrosion, environmental pollution, expensive reagents used, tedious workup procedures, excessive dependency on fossil resource, etc. [16-29]. Herein, the support originated from the renewable feedstock will be one of the promising candidates for the preparation of solid amine catalysts in the field of the continuous production of high value-added chemicals through Knoevenagel condensation reaction.

Sugarcane bagasse (SCB), as a typical agriculture waste, contains a lot of hydroxyl groups $(-\mathrm{OH})$ due to its primary components of cellulose $(40-50 \%)$, hemicellulose $(25-35 \%)$, and lignin $(15-20 \%)$ [30]. It is an ideal renewable catalyst support for the fabrication of the solid catalyst through a simple amine silanization process. Herein, based on our previous studies on the utilization of the biomass resource [31-33], an amine-functionalized sugarcane bagasse, denoted as SCB- $\mathrm{NH}_{2}$, has been designed and utilized in the continuous flow Knoevenagel condensation reaction at room temperature. The Knoevenagel condensation between benzaldehyde and malononitrile was set as the model reaction in batch and flow reaction systems. The physicochemical properties and catalytic performance of SCB-NH$H_{2}$ in batch and continuous flow conditions have been investigated carefully.

\section{Results and Discussion}

\subsection{Characterization of $\mathrm{SCB}-\mathrm{NH}_{2}$}

Fourier transform infrared (FT-IR) spectra of primary SCB and SCB- $\mathrm{NH}_{2}$ are shown in Figure 1. Peaks at 3400, 2915 and $2885 \mathrm{~cm}^{-1}$ for SCB are due to stretching of $-\mathrm{OH},-\mathrm{CH}_{3}$, and $-\mathrm{CH}_{2}$ groups, respectively (Figure1a) [34]. Peaks at 1427, 1398, 1163, 1058, and $898 \mathrm{~cm}^{-1}$ are assigned to the characteristic vibrations of cellulose [35]; and the peak at $1735 \mathrm{~cm}^{-1}$ is assigned to the stretching vibration of acetyl groups attached to hemicellulose in the raw material [36]. Signals at 1634, 1605, $1511,1458,1324,1264,1200,1116$, and $832 \mathrm{~cm}^{-1}$ are ascribed to the characteristic vibrations of aromatic rings in lignin [37]. The results are in agreement with the primary component of SCB (Table S1). 


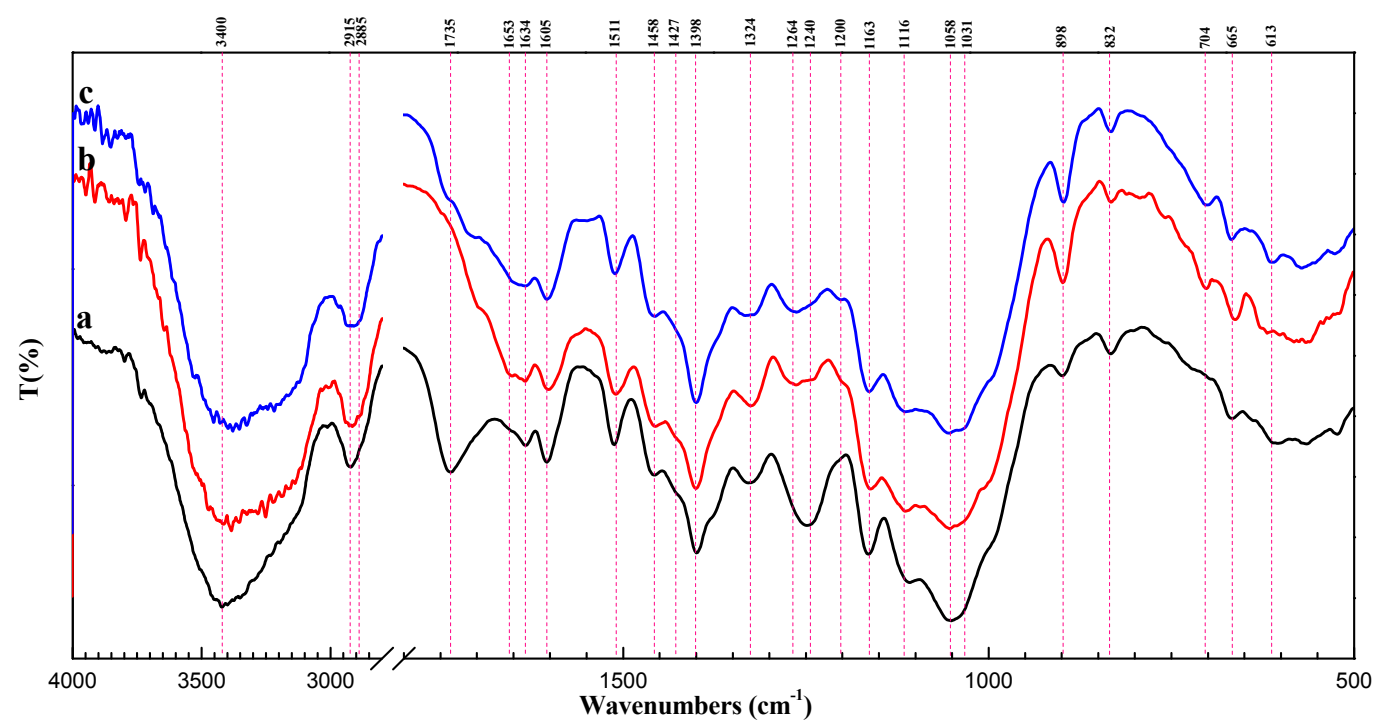

Figure 1. FT-IR spectra of SCB (a), fresh SCB-NH 2 (b), and recovered SCB- $\mathrm{NH}_{2}$ (c).

After the amination of SCB with (3-chloropropyl)trimethoxysilane (CTEOS) and ethylenediamine (Figure $1 \mathrm{~b}$ ), the absorbance at $1735 \mathrm{~cm}^{-1}$ for acetyl group in the spectrum of $\mathrm{SCB}-\mathrm{NH}_{2}$ disappeared, implying the completed deacetylation of hemicellulosic fraction under the alkaline condition for the amination process [38]. Furthermore, from the spectra of SCB before and after the amination, no bands assigned to $\mathrm{N}-\mathrm{H}$ stretching and bending are observed in the range of $3500-3000 \mathrm{~cm}^{-1}$ and $1700-1300 \mathrm{~cm}^{-1}$ beside the weak absorbance at $1653 \mathrm{~cm}^{-1}$. This could be caused by the strong absorbance of hydroxyl group which overlaps the absorbance of $\mathrm{N}-\mathrm{H}$ from SCB- $\mathrm{NH}_{2}$. The absorbance at $1653 \mathrm{~cm}^{-1}$ was assigned to the deformation vibrations of secondary amines [39], confirming the successful animation of SCB with amine group $\left(-\mathrm{NH}_{2}\right)$.

To deeply understand the amine content, the $\mathrm{SCB}$ and $\mathrm{SCB}-\mathrm{NH}_{2}$ were also analyzed by elemental analysis (Table 1). Before the amination, the nitrogen element $(\mathrm{N})$ content in SCB is only $0.19 \%$, which is attributed to a minor amount of protein in the primary SCB [40-42]. After the amination, the $\mathrm{N}$ content increases to $1.98 \%$, confirming the successful grafting of $-\mathrm{NH}_{2}$ groups onto $\mathrm{SCB}$. Comparing with the $\mathrm{N}$ content in SCB, the increment of $1.79 \%$ in the $\mathrm{N}$ content in SCB- $\mathrm{NH}_{2}$ corresponds to $1.28 \mathrm{mmol}$ of $-\mathrm{NH}_{2}$ group in $1 \mathrm{~g}$ of SCB-NH${ }_{2}$ catalyst. Combined with the result of FT-IR and elemental analysis, the successful preparation of SCB- $\mathrm{NH}_{2}$ is further verified.

Table 1. The element analysis of SCB, fresh SCB-NH $\mathrm{N}_{2}$, and recovered SCB-NH .

\begin{tabular}{|c|c|c|c|}
\hline \multirow{2}{*}{ Samples } & \multicolumn{3}{|c|}{ Element Content (wt. \%) } \\
\hline & $\mathrm{C}$ & $\mathbf{H}$ & $\mathbf{N}$ \\
\hline SCB & $41.52 \pm 0.22$ & $7.97 \pm 0.07$ & $0.19 \pm 0.02$ \\
\hline Fresh SCB-NH$H_{2}$ & $41.24 \pm 0.30$ & $8.00 \pm 0.05$ & $1.98 \pm 0.01$ \\
\hline Recovered SCB-NH ${ }_{2}$ & $41.74 \pm 0.24$ & $7.98 \pm 0.06$ & $1.82 \pm 0.01$ \\
\hline
\end{tabular}

To evaluate the stability of SCB in the amination process, the crystalline structure of SCB before and after the amination was investigated through powder X-ray diffraction (XRD) methods (Figure 2). For SCB, three peaks at $15.9,22.1,34.7^{\circ}$ are observed, which are attributed to cellulose I crystal [35]. These peaks are also observed in the XRD pattern of SCB- $\mathrm{NH}_{2}$, indicating SCB is stable in this two-step amination process. 


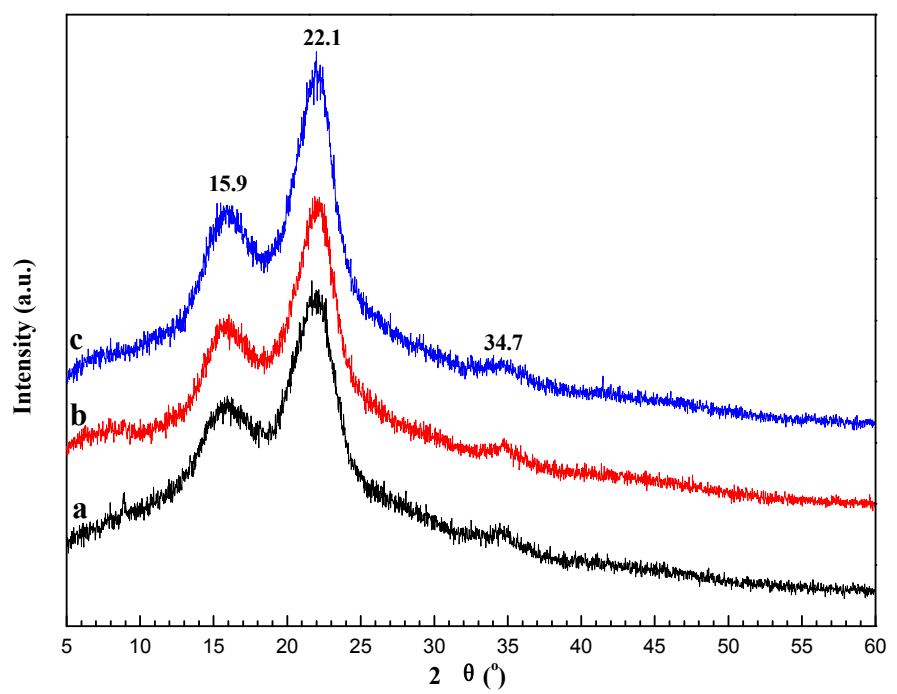

Figure 2. XRD patterns of SCB (a), fresh $\mathrm{SCB}-\mathrm{NH}_{2}(\mathbf{b})$, and recovered $\mathrm{SCB}-\mathrm{NH}_{2}$ (c).

The thermal stabilities of SCB and SCB- $\mathrm{NH}_{2}$ were also investigated by thermogravimetry analysis method (TG). The thermal decomposition profiles are presented in Figure 3. In all samples, the first weight loss stage below $100{ }^{\circ} \mathrm{C}$ was $\sim 5 \%$, which is associated with the evaporation of water adsorbed in the samples. As for SCB sample, the second weight loss stage $(\sim 64 \%)$ started at $250{ }^{\circ} \mathrm{C}$ and then proceeded rapidly below $350{ }^{\circ} \mathrm{C}$. At $800{ }^{\circ} \mathrm{C}$, refractory constituents $(\sim 12 \%)$ such as tar and/or char and inorganic salts remained. Weight loss peaking at $315^{\circ} \mathrm{C}$ in the differential thermogravimetry (DTG) curve indicates the rapid decomposition of hemicellulose, cellulose and lignin in raw material [43]. The second weight loss stage of SCB- $\mathrm{NH}_{2}$ began at $260{ }^{\circ} \mathrm{C}$ and proceeded rapidly to the third weight loss stage at $325^{\circ} \mathrm{C}$ with weight loss of $20 \%$ and $35 \%$ respectively, leaving refractory constituents $(\sim 20 \%)$ containing tar and/or char, inorganic salts, and $\mathrm{SiO}_{2}$ at $800{ }^{\circ} \mathrm{C}$ [44]. The characteristic weight-loss peaks at $287^{\circ} \mathrm{C}$ and $360^{\circ} \mathrm{C}$ is due to the rapid decomposition of hemicellulose and grafted groups $\left(-\mathrm{NH}_{2},-\left(\mathrm{CH}_{2}\right)_{\mathrm{n}}-\right.$, etc. $)$. The weight-loss at $360{ }^{\circ} \mathrm{C}$ is possible caused by the combination of cellulose and lignin. This process for SCB- $\mathrm{NH}_{2}$ is $45^{\circ} \mathrm{C}$ higher than those in raw material showed above. This implies the protection effect of silicane coupling agent on SCB, which further illustrates that SCB support is stable in amination process.

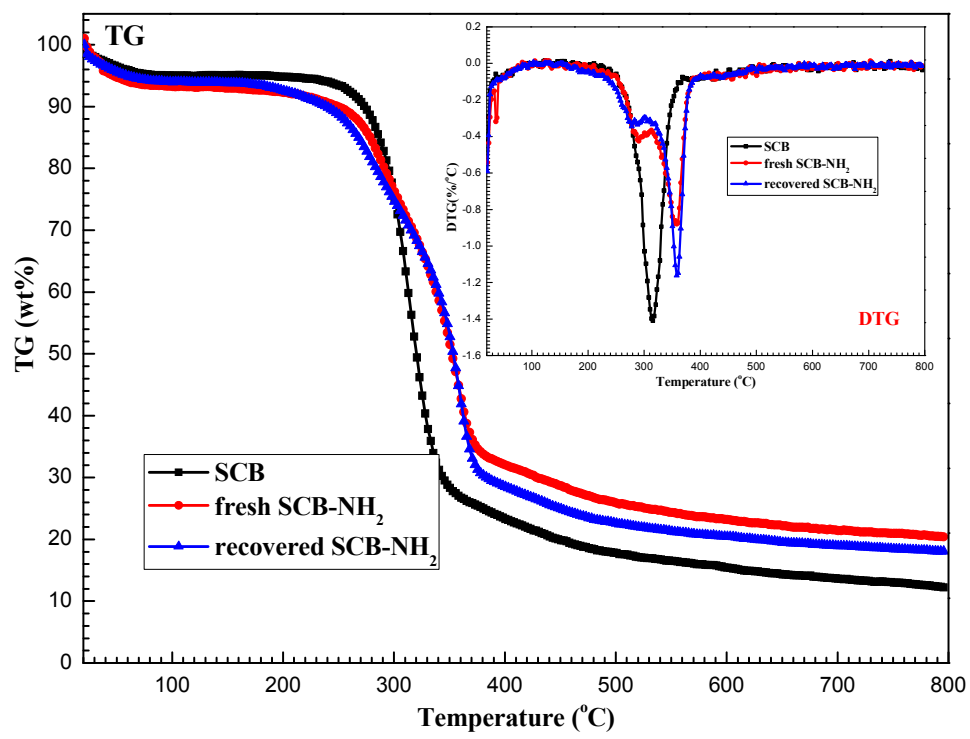

Figure 3. Thermal decomposition profiles of $\mathrm{SCB}$, fresh $\mathrm{SCB}-\mathrm{NH}_{2}$, and recovered SCB- $\mathrm{NH}_{2}$. 
The morphologies and surface characteristics of SCB and SCB- $\mathrm{NH}_{2}$ were also investigated by scanning electron microscope (SEM) and energy dispersive X-ray (EDX). The SEM images clearly showed that SCB possessed a smooth surface and compact morphology (Figure 4a). After being grafted with CTEOS and ethylenediamine, the surface was still smooth (Figure $4 \mathrm{~b}$ ), indicating the uniform distribution of silicane coupling agent on SCB. The direct evidence for the silicane coupling agent in SCB-NH $\mathrm{NH}_{2}$ is that silicon content increases to $4.16 \%$. Together with FT-IR and elemental analysis, the results from SEM and EDX further confirm the successful preparation of SCB-NH${ }_{2}$.

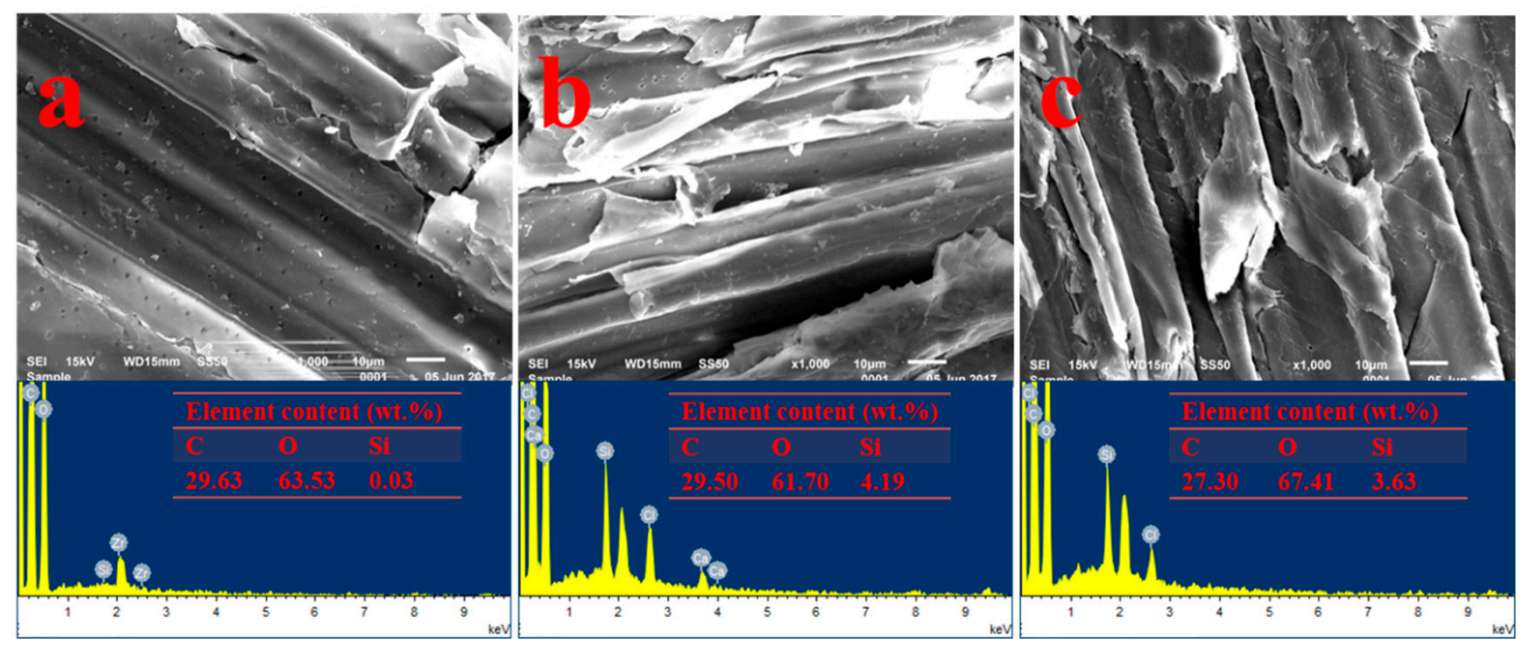

Figure 4. SEM images of SCB (a), fresh SCB-NH $2(\mathbf{b})$, and recovered SCB- $\mathrm{NH}_{2}(\mathbf{c})$.

Herein, on the basis of the above results, the as-prepared solid amine catalyst $\left(\mathrm{SCB}-\mathrm{NH}_{2}\right)$ with the $-\mathrm{NH}_{2}$ group as the active site is a constitutionally stable catalyst in the base catalysis field. The utilization of SCB- $\mathrm{NH}_{2}$ as the base catalyst for Knoevenagel condensation in batch and continuous flow processes was investigated in the following section.

\subsection{Catalytic Performance in Batch Reaction}

Before the investigation of the continuous flow Knoevenagel condensation, the catalytic performance of SCB- $\mathrm{NH}_{2}$ was firstly investigated in batch conditions. Table 2 showed the effect of catalyst dosage at room temperature $\left(25^{\circ} \mathrm{C}\right)$ on the reaction for the full conversion of benzaldehyde monitored by thin layer chromatography (TLC). In the absence of any catalyst, the reaction time was $10 \mathrm{~h}$ (Table 2, entry 1). After adding SCB- $\mathrm{NH}_{2}$, the reaction time reduced rapidly. When the amount of the added catalyst increased from 0.05 to $0.30 \mathrm{~g}$, the reaction time also decreased from 58 to $9 \mathrm{~min}$ (Table 2, entries 2-7). Noticeably, the yields of the isolated product in different reaction conditions were still higher than $80 \%$, implying the coexistence of side-reactions neglected. The catalytic performance of SCB and SCB-Cl for this base-catalyzed Knoevenagel condensation was also investigated (Table 2, entries 8 and 9). The results showed that both of two catalysts had certain catalytic activities for this condensation due to the activation effect of hydroxyl groups $(-\mathrm{OH})$ attached to the surface of SCB and SCB-Cl through the intermolecular hydrogen-bond effect $[26,45]$. However, the reaction time by using either SCB or SCB-Cl was still much longer than that for SCB- $\mathrm{NH}_{2}$ catalyst, demonstrating the $-\mathrm{NH}_{2}$ group was the dominant active center in $\mathrm{SCB}-\mathrm{NH}_{2}$ catalyst. 
Table 2. The influence of the catalyst dosage ${ }^{\mathrm{a}}$.

\begin{tabular}{|c|c|c|c|}
\hline Entry & Catalyst Dogase (g) & Time (min) & Yield (\%) ${ }^{b}$ \\
\hline 1 & - & $10 \pm 0.5(\mathrm{~h})$ & $89.2 \pm 2.4$ \\
\hline 2 & 0.05 & $58 \pm 5$ & $92.9 \pm 3.1$ \\
\hline 3 & 0.10 & $33 \pm 3$ & $94.3 \pm 2.8$ \\
\hline 4 & 0.15 & $15 \pm 2$ & $95.1 \pm 2.6$ \\
\hline 5 & 0.20 & $12 \pm 2$ & $94.1 \pm 3.2$ \\
\hline 6 & 0.25 & $10 \pm 1$ & $93.8 \pm 2.9$ \\
\hline 7 & 0.30 & $9 \pm 1$ & $94.3 \pm 2.1$ \\
\hline $8^{c}$ & 0.15 & $4 \pm 0.2(\mathrm{~h})$ & $94.9 \pm 2.6$ \\
\hline $9^{d}$ & 0.15 & $4 \pm 0.2(\mathrm{~h})$ & $87.9 \pm 2.7$ \\
\hline $10^{\mathrm{e}}$ & - & $28 \pm 1.5(\mathrm{~h})$ & $85.2 \pm 2.8$ \\
\hline
\end{tabular}

a Reaction conditions: $5.0 \mathrm{mmol}$ of benzaldehyde, $5.0 \mathrm{mmol}$ of malononitrile, $20 \mathrm{~mL}$ of $95 \% \mathrm{EtOH}$, room temperature $\left(25^{\circ} \mathrm{C}\right) ;{ }^{\mathrm{b}}$ Isolated yield; ${ }^{\mathrm{c}} \mathrm{SCB}$ as the catalyst; ${ }^{\mathrm{d}} \mathrm{SCB}-\mathrm{Cl}$ as the catalyst; ${ }^{\mathrm{e}}$ Without solvent.

The solvent effect on this reaction was also investigated. When no solvent was added into the catalyst-free system (Table 2, entry 10), the condensation reaction proceeded very slowly, the reaction time for the full conversion is as long as $28 \mathrm{~h}$. To understand the influence of solvent on this condensation reaction in depth, the solvent types and composition have been studied extensively (Table 3). From the green and economic chemistry point of view, the low boiling point and toxicity solvents, such as tetrahydrofuran (THF), acetone, methanol (MeOH), ethanol (EtOH) as outlined in the Pfizer solvent selection guide [46,47], have been selected as the "preferable" solvents.

Table 3. The influence of the solvent ${ }^{\mathrm{a}}$.

\begin{tabular}{|c|c|c|c|}
\hline Entry & Solvent & Time (min) & Yield (\%) ${ }^{b}$ \\
\hline 1 & - & $10 \pm 1$ & $95.2 \pm 1.9$ \\
\hline $2^{c}$ & THF & $>24(\mathrm{~h})$ & $51.5 \pm 2.1$ \\
\hline $3^{c}$ & Acetone & $>24(\mathrm{~h})$ & $54.3 \pm 3.2$ \\
\hline 4 & $\mathrm{MeOH}$ & $66 \pm 3$ & $93.3 \pm 2.7$ \\
\hline 5 & EtOH & $57 \pm 3$ & $94.1 \pm 2.5$ \\
\hline 6 & $98 \% \mathrm{EtOH}$ & $25 \pm 2$ & $94.3 \pm 2.8$ \\
\hline 7 & $95 \% \mathrm{EtOH}$ & $15 \pm 2$ & $95.1 \pm 2.6$ \\
\hline 8 & $90 \% \mathrm{EtOH}$ & $10 \pm 1$ & $94.1 \pm 2.3$ \\
\hline 9 & $80 \% \mathrm{EtOH}$ & $9 \pm 1$ & $93.8 \pm 3.1$ \\
\hline
\end{tabular}

a Reaction conditions: $5.0 \mathrm{mmol}$ of benzaldehyde, $5.0 \mathrm{mmol}$ of malononitrile, $0.15 \mathrm{~g}$ of SCB$-\mathrm{NH}_{2}, 20 \mathrm{~mL}$ of solvent, room temperature $\left(25^{\circ} \mathrm{C}\right){ }^{\mathrm{b}}$ Isolated yield; ${ }^{\mathrm{c}}$ the yield was determined by GC due to the incomplete conversion of benzaldehyde.

Table 3 showed that the molecular structure and composition of solvent had the important impact on the catalytic performance of SCB- $\mathrm{NH}_{2}$ in this condensation reaction. The condensation reaction was completed in only 10 min under the solvent-free system (Table 3, entry 1). However, when the aprotic solvents such as THF or acetone were added into the reaction system, the reaction proceeded very slowly. After $24 \mathrm{~h}$ there was still $\sim 50 \%$ of benzaldehyde remained in the reaction system (Table 3 , entries 2 and 3), demonstrating the unfavorable effect of aprotic solvents on this reaction. Subsequently, the protic $\mathrm{MeOH}$ and $\mathrm{EtOH}$ were used as the solvents. The catalytic performance of SCB- $\mathrm{NH}_{2}$ improved in a certain degree. However, the reaction time still reached up to about $60 \mathrm{~min}$ with more than $90 \%$ product yield (Table 3, entries 4 and 5). The water contained in the solvent or formed during this reaction facilitated the condensation process $[48,49]$. By using co-existence of water with protic solvent $(\mathrm{EtOH})$, the catalytic performance of $\mathrm{SCB}-\mathrm{NH}_{2}$ elevated significantly accompanying with 
$\sim 95 \%$ product yield. When $98 \%$ of $\mathrm{EtOH}$ was used as the solvent, the reaction time reduced to $25 \mathrm{~min}$ (Table 3, entry 6), which was much shorter than that in anhydrous solvent (57 min). Further increase of water content to $20 \%$ in the solvent, the reaction time for the full conversion of benzaldehyde is much shorter and reduced to 9 min (Table 3, entries 7-9).

However, as the water content increased, the solubility of product in the solvent decreased accordingly (Table S2). When the water content was more than 5\%, a certain amount of white solid was crystallized out before the reaction is completed (Figure S1), which limited the subsequent continuous flow reactions. Hence, on the basis of the results above, the commercially available $95 \% \mathrm{EtOH}$ was selected as the preferred solvent for the continuous flow reaction. It should be mentioned that the solubility of product in $95 \% \mathrm{EtOH}$ was $0.38 \mathrm{~g} / 10 \mathrm{~mL}$, which was in accordance with the theoretical product concentration in $20 \mathrm{~mL} \mathrm{95 \%} \mathrm{EtOH}$ with $5 \mathrm{mmol}$ of benzaldehyde and malononitrile as the starting materials.

In summary, considering the reaction time and product yield, the amount of catalyst added was $0.15-0.3 \mathrm{~g}$ and the reaction time ranges from 9 to $15 \mathrm{~min}$. The optimized batch was used as a guide for setting the residence time in continuous flow conditions with $95 \% \mathrm{EtOH}$ as the solvent.

\subsection{Continuous Flow Knoevenagel Condensation Reaction}

Based on the results from batch conditions, the concentration of raw material in the subsequent continuous flow reactions was $0.25 \mathrm{mmol} / \mathrm{mL}$ and the reaction was carried out in $95 \% \mathrm{EtOH}$ solvent at room temperature. The reactor is shown in Figures S2 and S3, and the amount of the catalyst filled in reactor was about $0.9 \mathrm{~g}$. The retention volume was about $5 \mathrm{~mL}$ determined by the volume method. According to the suggested residence time of 9 15 $\mathrm{min}$ in the batch reaction, the flow rate was firstly set as $0.5 \mathrm{~mL} / \mathrm{min}$.

As the flow rate was controlled at $0.5 \mathrm{~mL} / \mathrm{min}$, the complete conversion of benzaldehyde was achieved (Figure S4). This means the better catalytic performance of SCB- $\mathrm{NH}_{2}$ in continuous flow condition than that in batch condition at the same reaction time. The production capacity is an important criterion for evaluating the usability of continuous process. Hence, the higher flow rate in this flow process had been investigated inevitably. As the flow rate increased to $1.5 \mathrm{~mL} / \mathrm{min}$, the conversion of benzaldehyde was still as high as $99.5 \%$ and the product yield is over $99 \%$ (Figure S4). However, as the flow rate was more than $1.5 \mathrm{~mL} / \mathrm{min}$, the catalytic performance of this continuous system declined significantly. At the flow rate of $3.0 \mathrm{~mL} / \mathrm{min}$, the conversion of benzaldehyde was only $70.4 \%$, indicating its weak capability on catalytic conversion of a large amount of benzaldehyde in the relative short reaction time (residence time). It was noted that, the selectivity of product in all flow conditions was still more than $99.5 \%$, demonstrating the perfect conversion of benzaldehyde to product. Based on the above results, $1.5 \mathrm{~mL} / \mathrm{min}$ is the preferred flow rate for this continuous flow process, and was used to evaluate the tolerability of SCB- $\mathrm{NH}_{2}$ in time course (catalyst lifetimes).

The outflow solution was analyzed through nuclear magnetic resonance (NMR) and gas chromatography (GC) (Figures S5 and S6), and the results were given in Figure S7. It is demonstrated that no obvious deactivation was observed. The product yield and selectivity were over $97 \%$ and $99 \%$ after $80 \mathrm{~h}$, respectively, indicating its excellent catalytic stability. After the volatilization of solvent, the crude product was obtained as the white solid (Figure S8). Furthermore, the crude product was easily purified through recrystallization process in $95 \% \mathrm{EtOH}$, and the purity in the final product is over 99\% (Figure S9).

The catalyst was recovered after $120 \mathrm{~h}$ of flow reaction time, and further characterized through FT-IR (Figure 1c), elemental analysis (Table 1), XRD (Figure 2c), TG-DTG (Figure 3c), and SEM (Figure 4c). These results showed that the support (SCB) was very stable in this flow conditions. The slight deactivation after $80 \mathrm{~h}$ is attributed to the gradual loss of amine groups under flow conditions, which is proved by the elemental analysis. Therefore, the results above demonstrated that the as-prepared SCB- $\mathrm{NH}_{2}$ was a stable and efficient renewable catalyst for Knoevenagel condensation reaction under continuous flow conditions at room temperature (Scheme 1). 


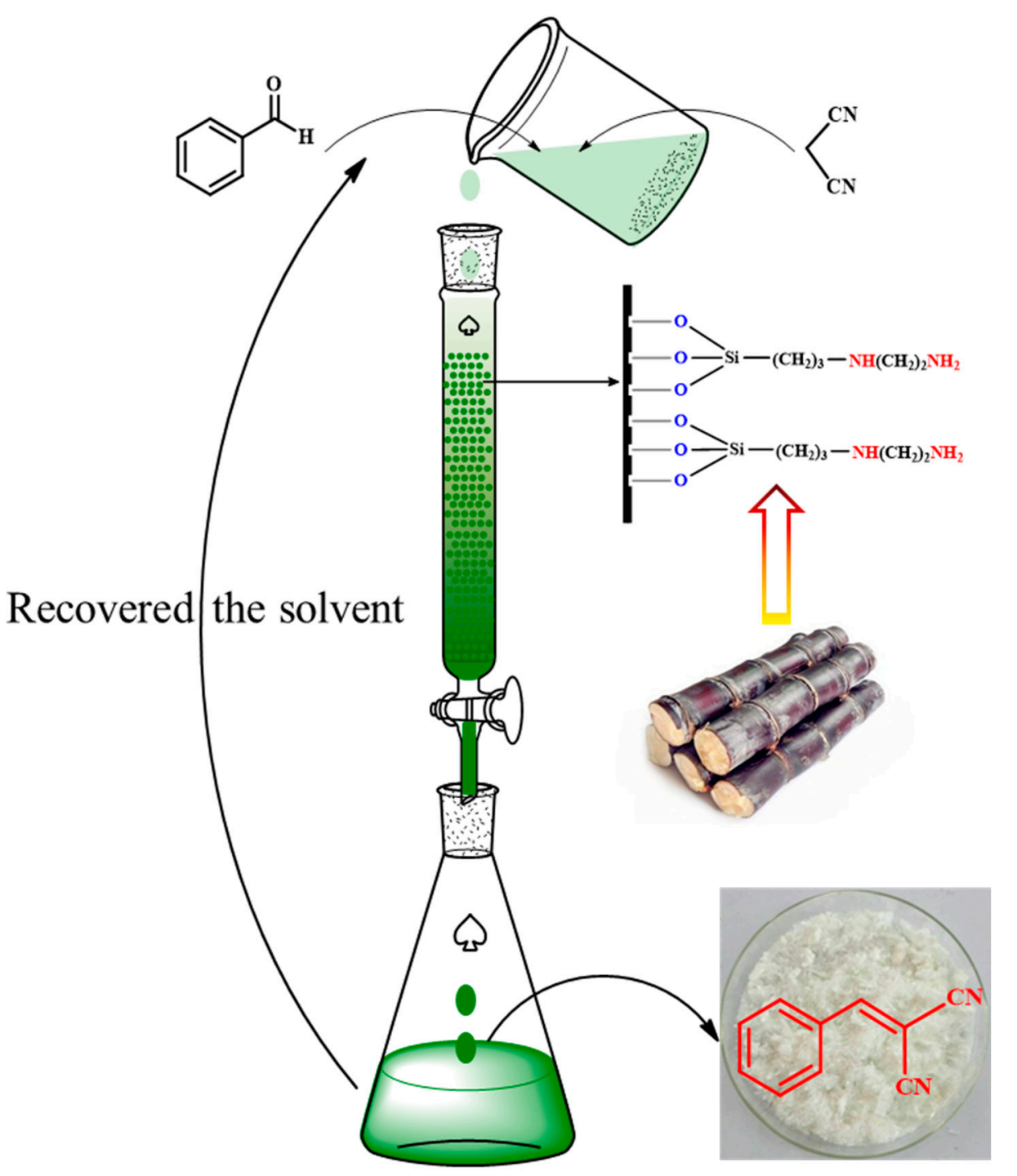

Scheme 1. Schematic diagram of continuous flow Knoevenagel reaction at room temperature.

Furthermore, the applicability of the SCB- $\mathrm{NH}_{2}$ catalyzed continuous flow Knoevenagel condensation reaction was also tested with different aldehydes. It was found that the glass chromatography column filled with $\mathrm{SCB}-\mathrm{NH}_{2}$ was not a suitable reactor for Knoevenagel reaction of furfural with malononitrile due to the rapid reaction rate and limited flow rate restricted by gravitational flow (Figure S10a). To realize the controllable condition, a waste chromatographic column installed in a high-performance liquid chromatography (HPLC) was used as a reactor instead of the glass reactor (Figure S10b), where the reaction condition, especially flow rate, can be controlled by HPLC instrument exactly (Figure S10b). Subsenquently, the resulting brown product from Knoevenagel condensation of furfural and malononitrile can be obtained after the recovery of solvent (Figure S10d). The results showed that the SCB- $\mathrm{NH}_{2}$ could be a potential substrate-tolerable catalytic material if a continuous reactor with controllable reaction conditions was adopted.

\section{Materials and Methods}

Benzaldehyde, malononitile, (3-chloropropyl)trimethoxysilane, and ethylenediamine were obtained from the J \& K Chemical Company; THF, acetone, $\mathrm{MeOH}, \mathrm{EtOH}$, and other agents were all purchased from Guangzhou Chemical Reagent Factory. The purity of these chemicals is more than $98 \%$ and used without purification. 
SCB was obtained from local Farm (Guigang, Guangxi Province, China). The primary ingredients of these SCB were analyzed according to TAPPI test method and listed in Table S1. Prior to use, SCB were dried under vacuum at $80^{\circ} \mathrm{C}$ for $24 \mathrm{~h}$. After being milled and sieved, the powder with particle sizes between 40-60 mesh was selected.

\subsection{Preparation and Characterization of $\mathrm{SCB}-\mathrm{NH}_{2}$}

As shown in Scheme 2, SCB- $\mathrm{NH}_{2}$ is first prepared by treating the dried SCB with (3-chloropropyl)trimethoxysilane (CTEOS) (step I) and then modified with ethylenediamine through the amination (step II) [50-53]. In a typical procedure, dried SCB (2.0 g) was first added into anhydrous toluene $(100 \mathrm{~mL})$, then $1.0 \mathrm{~g}(\sim 5.0 \mathrm{mmol})$ of (3-chloropropyl)trimethoxysilane and $0.1 \mathrm{~mL}(\sim 5.5 \mathrm{mmol})$ of $\mathrm{H}_{2} \mathrm{O}$ were added to this suspension, the mixture was further stirred and heated to reflux for $4 \mathrm{~h}$, subsequently, $1.5 \mathrm{~g}(\sim 25 \mathrm{mmol})$ ethylenediamine was added dropwise. After being refluxed for another $4 \mathrm{~h}$, the mixture was filtrated and washed by $\mathrm{EtOH}$ for three times and dried in vacuum oven at $80^{\circ} \mathrm{C}$ for $24 \mathrm{~h}$. The obtained material was denoted as $\mathrm{SCB}-\mathrm{NH}_{2}$.

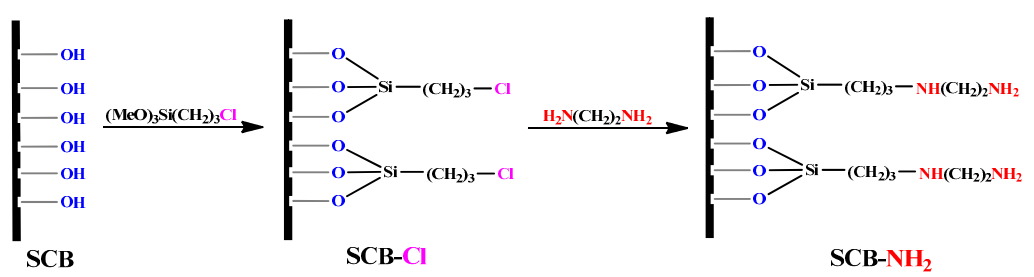

Scheme 2. Preparation of SCB-NH 2 .

The as-prepared catalyst was characterized by FT-IR, element analysis, XRD, TG and SEM-EDX. FT-IR spectroscopy was performed on a Thermo Nicolet 6700 spectrometer (Thermo Electron Corp., Waltham, MA, USA). The samples and KBr (spectral purity) were mixed at a ratio of 2:98 (w/w), ground, and pressed into a disc; then the FT-IR spectra were recorded using the disk in the range of $4000-400 \mathrm{~cm}^{-1}$ with a resolution of $4 \mathrm{~cm}^{-1}$. Elemental composition was analyzed through Vario EL cube Elemental analyzer (Elementar, Germany) to determine the content of the C, $H$, $\mathrm{N}$ elements presented in each sample and the amount of amine functionalities grafted onto SCB; the elemental analysis was repeated three times to minimize error. XRD patterns $\left(2 \theta=5-60^{\circ}\right)$ were measured on a Bruker AXS D8 Advance instrument (Karlsruhe, Germany) with Nickel-filtered CuK $\alpha$ (wavelength $=0.154 \mathrm{~nm}$ ) at $40 \mathrm{kV}$ and $40 \mathrm{~mA}$. The samples were mounted on a holder, and the proportional counter detector was set to collect data at a rate of $2 \theta=4^{\circ} / \mathrm{min}$ with increments of $0.04^{\circ}$ for $2 \theta$ values. TG profiles were measured on a Sta449 F3 thermogravimetric analyzer (Netzsch, Germany) using $\mathrm{N}_{2}$ flow of $50 \mathrm{~mL} / \mathrm{min}$ and a protective $\mathrm{N}_{2}$ flow of $30 \mathrm{~mL} / \mathrm{min}$. The samples are weighed about $10-15 \mathrm{mg}$, and were heated from 50 to $800{ }^{\circ} \mathrm{C}$ at a heating rate of $10{ }^{\circ} \mathrm{C} / \mathrm{min}$. SEM images were recorded with a JSM-6510LV SEM instrument (JEOL, Tokyo, Japan) with the combined EDX analyzer operated at an accelerating voltage of $15 \mathrm{kV}$ in a high-vacuum mode; prior to SEM observation, the samples were coated with gold by sputtered deposition using a Quick coater SC-701 (Sanyu Electron, Tokyo, Japan).

\subsection{Typical Batch Reaction}

Before the continuous flow reaction, the reaction condition was optimized in batch system. A $50 \mathrm{~mL}$ round bottomed flask was charged with $5.0 \mathrm{mmol}$ benzaldehyde, $5.0 \mathrm{mmol}$ malononitrile, $20 \mathrm{~mL} 95 \% \mathrm{EtOH}$, and $0.15 \mathrm{~g} \mathrm{SCB}-\mathrm{NH}_{2}$ catalyst. The reaction mixture was stirred at room temperature $\left(25{ }^{\circ} \mathrm{C}\right)$. The formation of the products was monitored by TLC, which was performed by using commercially available 100-400 mesh silica gel plates (GF254) with the visualization at 254 $\mathrm{nm}(3: 1(v / v)$ petroleum ether $\left(60-90^{\circ} \mathrm{C}\right)$ /ethyl acetate as the eluting agent). After reaction, the catalyst was filtered off and washed with $95 \% \mathrm{EtOH}(3 \times 10 \mathrm{~mL})$. The white crystals as the target product was obtained after 
recovery of the EtOH from the resulting filtrate. The product yield was calculated through comparing the weight of obtained product with theoretical value. To minimize errors, all experiments for batch conditions were repeated three times to calculate the mean values and standard deviations.

The structure and purity of product were analyzed by ${ }^{1} \mathrm{H}$ nuclear magnetic resonance $\left({ }^{1} \mathrm{HNMR}\right.$, Bruker DRX 400, $\mathrm{CDCl}_{3}$ as the solvent with $0.03 \%$ TMS as internal standard) and gas chromatography (GC, Shimadzu QP 2010, capillary column $(30 \mathrm{~m} \times 0.25 \mathrm{~mm}, 0.25 \mu \mathrm{m})$, FID detector and nitrogen as the carrier (flow rate of $1 \mathrm{~mL} / \mathrm{min}$ ); the injection volume was $0.1 \mu \mathrm{L}$; programmed oven temperature: hold at $100{ }^{\circ} \mathrm{C}$ for $1.0 \mathrm{~min}$, then ramped up to $220^{\circ} \mathrm{C}$ with the heating rate of $20{ }^{\circ} \mathrm{C} / \mathrm{min}$, then, hold at this temperature for $1.0 \mathrm{~min}$; injector: kept at $250^{\circ} \mathrm{C}$ in spit mode with spit ratio of 30:1).

\subsection{Continuous Flow Reaction}

Continuous flow Knoevenagel condensation was carried out at room temperature $\left(25^{\circ} \mathrm{C}\right)$ in a continuous flow glass chromatography column as shown in Figure S2. About $0.9 \mathrm{~g}$ of SCB-NH${ }_{2}$ catalyst was charged into the glass column (Figure S3), then the reactant mixture with equimolar benzaldehyde and malononitrile pre-dissolved in $95 \% \mathrm{EtOH}$ was added by a dropping funnel, and the flow rate was controlled by the stopcock of glass column. The product was collected in a flask and analyzed by ${ }^{1} \mathrm{H}$ NMR and GC at each given time interval. After the recovery of the $\mathrm{EtOH}$, a large amount of the white solid product was obtained. All experiments were replicated at least three times; the standard measurement uncertainties for NMR and GC analysis were less than $\pm 0.2 \%$ according to the repeated detection results.

\section{Conclusions}

Herein, a renewable catalyst, viz., SCB- $\mathrm{NH}_{2}$, was prepared successfully through a two-step amination process. The as-prepared SCB- $\mathrm{NH}_{2}$ exhibited high catalytic performance in liquid phase continuous flow Knoevenagel condensation at room temperature. At the flow rate of $1.5 \mathrm{~mL} / \mathrm{min}$, the as-constructed continuous flow system presented longer lifetimes $(\sim 80 \mathrm{~h})$ with excellent activity for perfect conversion of benzaldehyde into the product. It is believed that this renewable SCB- $\mathrm{NH}_{2}$ with excellent performance possesses potential and broad prospects in organic synthesis or catalysis. Hence, the results showed the SCB- $\mathrm{NH}_{2}$ is a promising catalyst for the synthesis of fine chemicals by Knoevenagel condensation reaction in large scale, and also confirmed the modification of renewable $\mathrm{SCB}$ with $-\mathrm{NH}_{2}$ group is a potential avenue for the preparation of amine-functionalized catalytic materials in industry. Moreover, by using the solid amine catalyst described here, further studies are currently underway in our group to extend both the substrates and reaction types such as Henry reaction, Michael addition, multicomponent reactions, etc., enabling more complex syntheses to be demonstrated in the future.

Supplementary Materials: The following are available online, Table S1: Primary ingredients of sugarcane bagasse, Table S2: The solubility of products in different solvent system, Figure S1: The photography of reaction mixture, Figure S2: The glass chromatography column, Figure S3: The photography of continuous flow reactor, Figure S4: The influence of flow rate on conversion and yield, Figure S5: ${ }^{1} \mathrm{H}$ NMR spectra of the products solution at different flow time, Figure S6: The GC profiles of outflow, Figure S7: Continuous flow Knoevenagel reaction at room temperature, Figure S8: The crude product obtained after recovered solvent, Figure S9: ${ }^{1} \mathrm{H}$ NMR spectra of the purified product, Figure S10: The continuous flow Knoevenagel condensation of furfural with malononitrile.

Acknowledgments: The authors gratefully acknowledge financial support of the Talent Introduction Program and PhD Research Startup Foundation of GDUPT (No. 2016rc06; 2017bs01), and the Ordinary University Innovation Project of Guangdong Province, China (No. 2015KTSCX091).

Author Contributions: Y.Q., H.M., S.W. conceived and designed the experiments; Y.Q., J.T., H.M. performed the experiments and analyzed the data; Y.Q., H.M., S.W. wrote the paper and proofread the manuscript.

Conflicts of Interest: The authors declare no conflict of interest. The founding sponsors had no role in the design of the study, in the collection, analyses, or interpretation of data and in the writing of the manuscript. 


\section{References}

1. Smith, M.B.; March, J. Advanced Organic Chemistry: Reactions, Mechanisms, and Structure, 6th ed.; Wiley: Hoboken, NJ, USA, 1968; pp. 1064-1065. ISBN 9780471720911.

2. Voskressensky, L.G.; Festa, A.A.; Varlamov, A.V. Domino reactions based on Knoevenagel condensation in the synthesis of heterocyclic compounds. Recent advances. Tetrahedron 2014, 70, 551-572. [CrossRef]

3. Jones, G. The Knoevenagel condensation. In Organic Reactions; John Wiley \& Sons: Hoboken, NJ, USA, 2011; Volume 15, pp. 204-599.

4. List, B. Emil Knoevenagel and the roots of aminocatalysis. Angew. Chem. Int. Ed. 2010, 49, $1730-1734$. [CrossRef] [PubMed]

5. Plutschack, M.B.; Pieber, B.; Gilmore, K.; Seeberger, P.H. The hitchhiker's guide to flow chemistry. Chem. Rev. 2017, 117, 11796-11893. [CrossRef] [PubMed]

6. Vaccaro, L.; Lanari, D.; Marrocchi, A.; Strappaveccia, G. Flow approaches towards sustainability. Green Chem. 2014, 16, 3680-3704. [CrossRef]

7. Aponteguzman, J.; Shenje, R.; Huang, Y.; Woodham, W.; Saunders, S.R.; Mostaghimi, S.; Flack, K.M.; Pollet, P.L.; Eckert, C.A.; Liotta, C.L. A tandem, bicatalytic continuous flow cyclopropanation-homo-nazarov-type cyclization. Ind. Eng. Chem. Res. 2015, 54, 9550-9558. [CrossRef]

8. Zhao, D.; Ding, K. Recent advances in asymmetric catalysis in flow. ACS Catal. 2013, 3, 928-944. [CrossRef]

9. Hessel, V.; Kralisch, D.; Kockmann, N.; Noël, T.; Wang, Q. Novel process windows for enabling, accelerating, and uplifting flow chemistry. ChemSusChem 2013, 6, 746-789. [CrossRef] [PubMed]

10. Wiles, C.; Watts, P. Continuous process technology: A tool for sustainable production. Green Chem. 2014, 16, 55-62. [CrossRef]

11. Newman, S.G.; Jensen, K.F. The role of flow in green chemistry and engineering. Green Chem. 2013, 15, 1456-1472. [CrossRef]

12. Christiaens, S.; Vantyghem, X.; Radoiu, M.; Vanden Eynde, J.J. Batch and continuous flow preparation of Hantzsch 1,4-dihydropyridines under microwave heating and simultaneous real-time monitoring by Raman spectroscopy. An exploratory study. Molecules 2014, 19, 9986-9998. [CrossRef] [PubMed]

13. Wiles, C.; Watts, P.; Haswell, S.J. An investigation into the use of silica-supported bases within EOF-based flow reactors. Tetrahedron 2004, 60, 8421-8427. [CrossRef]

14. Zhang, G.; Zhang, T.; Zhang, X.; Yeung, K.L. Continuous flow ZIF-8/NaA composite membrane microreactor for efficient Knoevenagel condensation. Catal. Commun. 2015, 68, 93-96. [CrossRef]

15. Tsutsumi, Y.; Koga, H.; Qi, Z.D.; Saito, T.; Isogai, A. Nanofibrillar chitin aerogels as renewable base catalysts. Biomacromolecules 2014, 15, 4314-4319. [CrossRef] [PubMed]

16. Xu, D.Z.; Shi, S.; Wang, Y. Polystyrene-immobilized DABCO as a highly efficient and recyclable organocatalyst for the Knoevenagel condensation reaction. RSC Adv. 2013, 3, 23075-23079. [CrossRef]

17. Parida, K.M.; Rath, D. Amine functionalized MCM-41: An active and reusable catalyst for Knoevenagel condensation reaction. J. Mol. Catal. A Chem. 2009, 310, 93-100. [CrossRef]

18. Martins, L.; Hölderich, W.; Hammer, P.; Cardoso, D. Preparation of different basic Si-MCM-41 catalysts and application in the Knoevenagel and Claisen-Schmidt condensation reactions. J. Catal. 2010, 271, 220-227. [CrossRef]

19. Gascon, J.; Aktay, U.; Hernandez-Alonso, M.D.; Klink, G.P.M.V.; Kapteijn, F. Amino-based metal-organic frameworks as stable, highly active basic catalysts. J. Catal. 2009, 261, 75-87. [CrossRef]

20. Nguyen, L.T.L.; Le, K.K.A.; Truong, H.X.; Phan, N.T.S. Metal-organic frameworks for catalysis: The Knoevenagel reaction using zeolite imidazolate framework ZIF-9 as an efficient heterogeneous catalyst. Catal. Sci. Technol. 2012, 2, 521-528. [CrossRef]

21. Yang, Y.; Yao, H.F.; Xi, F.G.; Gao, E.Q. Amino-functionalized Zr(IV) metal-organic framework as bifunctional acid-base catalyst for Knoevenagel condensation. J. Mol. Catal. A Chem. 2014, 390, 198-205. [CrossRef]

22. Ren, Y.; Lu, J.; Jiang, O.; Cheng, X.; Chen, J. Amine-grafted on lanthanide metal-organic frameworks: Three solid base catalysts for Knoevenagel condensation reaction. Chin. J. Catal. 2015, 36, 1949-1956. [CrossRef]

23. Li, G.; Xiao, J.; Zhang, W. Efficient and reusable amine-functionalized polyacrylonitrile fiber catalysts for Knoevenagel condensation in water. Green Chem. 2012, 14, 2234-2242. [CrossRef] 
24. Xue, B.; Zhu, J.; Liu, N.; Li, Y. Facile functionalization of graphene oxide with ethylenediamine as a solid base catalyst for Knoevenagel condensation reaction. Catal. Commun. 2015, 64, 105-109. [CrossRef]

25. Rana, S.; Jonnalagadda, S.B. Synthesis and characterization of amine functionalized graphene oxide and scope as catalyst for Knoevenagel condensation reaction. Catal. Commun. 2017, 92, 31-34. [CrossRef]

26. Huh, S.; Chen, H.T.; Wiench, J.W.; Pruski, M.; Lin, V.S. Cooperative catalysis by general acid and base bifunctionalized mesoporous silica nanospheres. Angew. Chem. 2005, 117, 1860-1864. [CrossRef]

27. Rostami, A.; Atashkar, B.; Gholami, H. Novel magnetic nanoparticles $\mathrm{Fe}_{3} \mathrm{O}_{4}$-immobilized domino Knoevenagel condensation, Michael addition, and cyclization catalyst. Catal. Commun. 2013, 37, 69-74. [CrossRef]

28. Varadwaj, G.B.; Rana, S.; Parida, K.M. Amine functionalized K10 montmorillonite: A solid acid-base catalyst for the Knoevenagel condensation reaction. Dalton Trans. 2013, 42, 5122-5129. [CrossRef] [PubMed]

29. Zhu, F.; Sun, X.; Lou, F.; An, L.; Zhao, P. Facile one-pot synthesis of amine-functionalized mesoporous silica nanospheres for water-medium Knoevenagel reaction under microwave irradiation. Catal. Lett. 2015, 145, 1072-1079. [CrossRef]

30. Tadesse, H.; Luque, R. Advances on biomass pretreatment using ionic liquids: An overview. Energy Environ. Sci. 2011, 4, 3913-3929. [CrossRef]

31. Ma, H.; Wang, F.; Yu, Y.; Wang, L.; Li, X. Autocatalytic production of 5-hydroxymethylfurfural from fructose-based carbohydrates in a biphasic system and its purification. Ind. Eng. Chem. Res. 2015, 54, 2657-2666. [CrossRef]

32. Teng, J.; Ma, H.; Wang, F.; Wang, L.; Li, X. Catalytic fractionation of raw biomass to biochemicals and organosolv lignin in a methyl isobutyl ketone $/ \mathrm{H}_{2} \mathrm{O}$ biphasic system. ACS Sustain. Chem. Eng. 2016, 4, 2020-2026. [CrossRef]

33. Teng, J.; Ma, H.; Wang, F.; Wang, L.; Li, X. A facile and eco-effective catalytic system for synthesis of 5-hydroxymethylfurfural from gucose. Bioresources 2016, 11, 2152-2165. [CrossRef]

34. Fushimi, C.; Katayama, S.; Tasaka, K.; Suzuki, M.; Tsutsumi, A. Elucidation of the interaction among cellulose, xylan, and lignin in steam gasification of woody biomass. AIChE J. 2009, 55, 529-537. [CrossRef]

35. Liu, R.; Yu, H.; Huang, Y. Structure and morphology of cellulose in wheat straw. Cellulose 2005, 12, 25-34. [CrossRef]

36. Yuan, T.Q.; Xu, F.; He, J.; Sun, R.C. Structural and physico-chemical characterization of hemicelluloses from ultrasound-assisted extractions of partially delignified fast-growing poplar wood through organic solvent and alkaline solutions. Biotechnol. Adv. 2010, 28, 583-593. [CrossRef] [PubMed]

37. Tejado, A.; Peña, C.; Labidi, J.; Echeverria, J.M.; Mondragon, I. Physico-chemical characterization of lignins from different sources for use in phenol-formaldehyde resin synthesis. Bioresour. Technol. 2007, 98, 1655-1663. [CrossRef] [PubMed]

38. Luo, S.; Chen, S.; Chen, S.; Zhuang, L.; Ma, N.; Xu, T.; Li, Q.; Hou, X. Preparation and characterization of amine-functionalized sugarcane bagasse for $\mathrm{CO}_{2}$ capture. J. Environ. Manag. 2016, 168, 142-148. [CrossRef] [PubMed]

39. Pacheco, D.M.; Johnson, J.R.; Koros, W.J. Aminosilane-functionalized cellulosic polymer for increased carbon dioxide sorption. Ind. Eng. Chem. Res. 2012, 51, 503-514. [CrossRef]

40. Ribeiro, M.A.; Oikawa, H.; Mori, M.N.; Napolitano, C.M.; Duarte, C.L. Degradation mechanism of polysaccharides on irradiated sugarcane bagasse. Radiat. Phys. Chem. 2013, 84, 115-118. [CrossRef]

41. Fonsecamaldonado, R.; Ribeiro, L.F.; Furtado, G.P.; Arruda, L.M.; Meleiro, L.P.; Alponti, J.S.; Botelhomachado, C.; Vieira, D.S.; Bonneil, E.; Furriel, R.D.P.M. Synergistic action of co-expressed xylanase/laccase mixtures against milled sugar cane bagasse. Process Biochem. 2014, 49, 1152-1161. [CrossRef]

42. Rocha, G.J.D.M.; Nascimento, V.M.; Gonçalves, A.R.; Silva, V.F.N.; Martín, C. Influence of mixed sugarcane bagasse samples evaluated by elemental and physical-chemical composition. Ind. Crop. Prod. 2015, 64, 52-58. [CrossRef]

43. Chen, Y.; Sun, L.; Negulescu, I.I.; Moore, M.A.; Collier, B.J. Evaluating efficiency of alkaline treatment for waste bagasse. J. Macromol. Sci. B 2005, 44, 397-411. [CrossRef]

44. Chen, J.H.; Xing, H.T.; Guo, H.X.; Li, G.P.; Weng, W.; Hu, S.R. Preparation, characterization and adsorption properties of a novel 3-aminopropyltriethoxysilane functionalized sodium alginate porous membrane adsorbent for Cr(III) ions. J. Hazard. Mater. 2013, 248-249, 285-294. [CrossRef] [PubMed] 
45. Ying, A.; Ni, Y.; Xu, S.; Liu, S.; Yang, J.; Li, R. Novel DABCO-based ionic liquids: Green and efficient catalysts with dual catalytic roles for aqueous Knoevenagel condensation. Ind. Eng. Chem. Res. 2014, 53, 5678-5682. [CrossRef]

46. Alfonsi, K.; Colberg, J.; Dunn, P.J.; Fevig, T.; Jennings, S.; Johnson, T.A.; Kleine, H.P.; Knight, C.; Nagy, M.A.; Perry, D.A. Green chemistry tools to influence a medicinal chemistry and research chemistry-based organisation. Green Chem. 2008, 10, 31-36. [CrossRef]

47. Henderson, R.K.; Jiménezgonzález, C.; Constable, D.J.C.; Alston, S.R.; Inglis, G.G.A.; Fisher, G.; Sherwood, J.; Binks, S.P.; Curzons, A.D. Expanding GSK's solvent selection guide-Embedding sustainability into solvent selection starting at medicinal chemistry. Green Chem. 2011, 13, 854-862. [CrossRef]

48. Zhao, X.L.; Yang, K.F.; Zhang, Y.P.; Zhu, J.; Xu, L.W. Sevelamer as an efficient and reusable heterogeneous catalyst for the Knoevenagel reaction in water. Chin. Chem. Lett. 2014, 25, 1141-1144. [CrossRef]

49. Zhang, Y.; Zhang, J.; Tian, M.; Chu, G.; Quan, C. Fabrication of amino-functionalized $\mathrm{Fe}_{3} \mathrm{O}_{4} @ \mathrm{Cu}_{3}(\mathrm{BTC})_{2}$ for heterogeneous Knoevenagel condensation. Chin. J. Catal. 2016, 37, 420-427. [CrossRef]

50. Zhang, Q.; Su, H.; Luo, J.; Wei, Y. A magnetic nanoparticle supported dual acidic ionic liquid: A "quasi-homogeneous" catalyst for the one-pot synthesis of benzoxanthenes. Green Chem. 2012, 14, 202-208. [CrossRef]

51. Koga, H.; Kitaoka, T.; Isogai, A. In situ modification of cellulose paper with amino groups for catalytic applications. J. Mater. Chem. 2011, 21, 9356-9361. [CrossRef]

52. Wu, Y.; Zhen, L.; Xia, C. Silica-gel-supported dual acidic ionic liquids as efficient catalysts for the synthesis of polyoxymethylene dimethyl ethers. Ind. Eng. Chem. Res. 2016, 55, 1859-1865. [CrossRef]

53. Koga, H.; Kitaoka, T.; Isogai, A. Chemically-modified cellulose paper as a microstructured catalytic reactor. Molecules 2015, 20, 1495-1508. [CrossRef] [PubMed]

Sample Availability: Samples of the compounds are not available from the authors.

(C) 2017 by the authors. Licensee MDPI, Basel, Switzerland. This article is an open access article distributed under the terms and conditions of the Creative Commons Attribution (CC BY) license (http:// creativecommons.org/licenses/by/4.0/). 